\title{
OS PROGRAMAS DE PÓS-GRADUACÃO EM ANTROPOLOGIA SOCIAL DO MUSEU NACIONAL, UNIVERSIDADE DE BRASÍLIA, UNIVERSIDADE DE SÃO PAULO E UNIVERSIDADE ESTADUAL DE CAMPINAS
}

\section{Christina de Rezende Rubim}

\section{Universidade Federal de Uberlândia - Brasil}

Resumo: O artigo apresenta a história dos primeiros quatro programas de pós-graduação em Antropologia Social criados no Brasil a partir da Reforma do Ensino na segunda metade da década de 60 através de suas respectivas dissertações de mestrado e das diferentes gerações intelectuais em cada instituição.

Abstract: This article presents the history of the first four M. A. Programs in Social Anthropology in Brazil starting from the Teaching Rerform, carried out in the late sixties, and proceeding with the analysis of each program's dissertations, taking into consideration the different intellectual generations in each institution.

\section{Introdução}

Uma das características da pós-graduação antes da reforma do ensino no final dos anos 60, era que a formação de pesquisadores de alto nível dependia mais de esforços individuais do que institucionais. No Brasil, o período do pós-guerra e o novo formato que assumiu a economia internacional

\footnotetext{
1 Este artigo é parte do capítulo conclusivo de minha tese de doutorado em Ciências Sociais, Antropólogos brasileiros e a antropologia no Brasil: a lira da pós-graduação, defendida em agosto de 1996 na Unicamp com a orientação de Mariza Corrêa. O principal objetivo da pesquisa era o de construir um panorama crítico da produção antropológica brasileira através das dissertações de mestrado defendidas nos Programas de Pós-Graduações em Antropologia Social/PPGAS do Museu Nacional, Universidade de Brasília, Universidade de São Paulo e Universidade Estadual de Campinas a partir de suas criações na virada dos anos 60/70 até 1994, a reconstrução de suas histórias e das trajetórias intelectuais de seus principais professores. Os quatro PPGAS escolhidos foram os primeiros a serem criados no Brasil e conjuntamente somam 76\% da produção da disciplina no país até 1994.
} 
contribuíram para que se criassem as condições para o desenvolvimento da pós-graduação no período posterior: fundação das universidades federais, católicas, institutos de pesquisas, associações profissionais. ${ }^{2}$ Conselho Nacional de Pesquisa/CNPq, Coordenação de Aperfeiçoamento de Pessoal de Nível Superior/CAPES e o aumento da população universitária.

A era da pós-graduação inaugurou uma fase de formação profissional no sentido de capacitação institucional - financeira, orientação sistemática, cursos, bibliotecas etc. - que qualitativamente transformou o caráter da pesquisa científica no país. ${ }^{3}$ Do autodidatismo do período anterior, passou-se a uma fase de iniciativas institucionais.

A antropologia, anteriormente à institucionalização dos programas de pós-graduação, estava restrita a pequenos grupos como o do Museu Nacional/ Universidade Federal do Rio de Janeiro/UFRJ, da Universidade de São Paulo/ $U_{S P}^{4}$ e da Escola de Sociologia e Política de São Paulo. No caso paulista, a antropologia caminhava conjuntamente com as orientações presentes na sociologia, que servia de referência para as demais ciências sociais, no que se convencionou chamar de "Escola de Sociologia Paulista"5 pela própria especificidade histórica de criação da Universidade de São Paulo e do grupo de intelectuais franceses que contribuíram para esta formação. A tradição funcional-culturalista, na época, fez com que a vertente antropológica de Florestan

2 Como, por exemplo, a Sociedade Brasileira de Sociologia/SBS em 1950 e a Associação Brasileira de Antropologia/ABA em 1954.

3 Ao contrário do que aconteceu no mesmo período em países da América Latina como, por exemplo, México e Argentina, onde a tradição de uma graduação em antropologia contrasta com a incipiência dos estudos pós-graduados. Ver especialmente Ratier e Stagnaro (1996) e Rabiela (1996) que compararam as suas respectivas tradições numa Mesa Redonda organizada para a XX Reunião da ABA (1996) em Salvador, Bahia.

4 A USP foi criada pelas elites paulistanas em 1934 e a então Faculdade de Filosofia, Ciências e Letras contou com a presença da Missão Francesa que tinha Claude Lévi-Strauss como um de seus representantes. Ver sobre a história da USP: Souza Campos (1954), Fernandes (1984), Araújo (1980) Irene Cardoso (1982), Loschiavo dos Santos (1988), Limongi (1989), Massi (1989), Paulo Arantes (1994), Roberto Schwarcz (1995), Rubim (1996) entre outros.

5 Segundo Egon Schaden (1984, p. 254): "Nunca chegou a esboçar-se, felizmente, na Universidade de São Paulo, algo que pudesse denominar-se 'escola antropológica paulista'. Por sorte, os interesses foram sempre variados, com tendência crescente para estudos interdisciplinares. Desde cedo se acentuou, entretanto, a perspectiva sociológica, por influência, principalmente, de Claude Lévi-Strauss, que, vindo em 1935, era oficialmente professor de sociologia. Não tardou a ser fascinado pelos temas antropológicos, para os quais acabou convergindo quase todo o seu ensino. Por esse e outros antecedentes, continua a antropologia em São Paulo como conjunto de disciplinas vinculadas predominantemente, pelo menos de forma indireta, a estudos sociais e políticos.”

Horizontes Antropológicos, Porto Alegre, ano 3, n. 7, p. 97-128, nov. 1997 
Fernandes, ${ }^{6}$ por exemplo, fosse deixada de lado pelos estudiosos das ciências sociais, priorizando-se as pesquisas sociológicas do autor.

Alguns intelectuais formados nessa tradição e que escolheram as ciências sociais como profissão, transferiram-se para o Rio de Janeiro na década de 50/60 - como na antropologia, Roberto Cardoso de Oliveira que Foi para o Museu Nacional - e levaram consigo uma concepção de ciência social aprendida e praticada em São Paulo com os mestres franceses. Os anos 60 - momento fundamental e de transição quanto às definições metodológicas que iriam se consolidar no período seguinte - foi um período em que o estruturalismo francês começou a se projetar nas ciências sociais, particularmente na antropologia e, através desta disciplina, começou a influenciar o pensamento social brasileiro.

Um outro espaço da antropologia carioca, foi aquele formado pela Cadeira de Antropologia e Etnologia da Faculdade Nacional de Filosofia da UFRJ, composta, principalmente, pelo grupo ligado a Arthur Ramos, este influenciado por autores norte-americanos como Melville Herskovits. ${ }^{7}$ É interessante perceber como a corrente do pensamento antropológico que privilegiava o conceito de cultura ${ }^{8}$ e o desenvolvimento ¡solado dos grupos sociais, praticamente hegemônica até esse período, quase desapareceu na década seguinte. Refiro-me ao culturalismo norte-americano, que teve em Darcy Ribeiro um de seus mais eminentes representantes.

Com a reforma do ensino e a implantação dos Programas de PósGraduação em Antropologia Social/PPGAS na segunda metade dos anos 60, a disciplina conquistou um espaço temático e uma identidade fortemente delimitada por um estilo antropológico de fazer pesquisa ${ }^{9}$ e, mais particularmente, pela supervalorização da observação participante que seguiu a tradição antropológica de Malinowski e Boas.

6 Ver Peirano (1981).

7 Veja sobre este assunto o livro de Paulo Roberto Azeredo (1986).

8 Ver Cardoso de Oliveira (1988) sobre o desenvolvimento da antropologia, seus principais personagens e conceitos mais utilizados, na primeira metade deste século. Ver também o texto de Corrêa (1987).

9 Muitas vezes este estilo de fazer pesquisa tem sido criticado por alguns cientistas sociais. Como exemplo temos a Mesa Redonda Teoria e Método e as Ciências Sociais Brasileiras na Atualidade realizada na XIV Encontro Anual da ANPOCS, em outubro de 1990, Caxambu/MG. Participaram do evento Mariza Peirano, Luiz Felipe de Alencastro, Simon Schwartzman, Fábio Wanderley Reis (expositores) e Vilmar Faria (debatedor). A polêmica iniciada entre Reis (ciência política) e Peirano (antropologia social) foi novamente retomada no XVIII Encontro Anual da ANPOCS no Fórum O Ensino das Ciências Sociais em Questão: O Caso da Antropologia. Ver textos de Peirano (1991), Alencastro (1991), Schwartzman (1991) e Reis (1991).

Horizontes Antropológicos, Porto Alegre, ano 3, n. 7, p. 97-128, nov. 1997 
Dissertacõoes de mestrado no MN, USP, Unicamp e UNB (décadas de 70/80/90, até 1994).

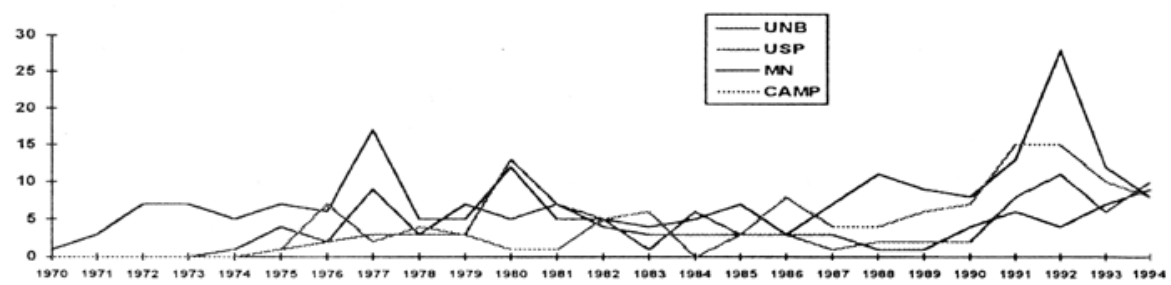

A criação da pós-graduação, não teve como base um ensino de graduação consolidado ${ }^{10}$ e com claros objetivos profissionais, mas sim uma produção de pesquisas relativamente sedimentada, principalmente nos museus. Contudo, justamente pelo espaço que nossos autores souberam inteligentemente ocupar, o primeiro Programa de Pós-Graduação em Antropologia Social nasceu forte e com conceito "A" (Woortmann, 1993), criando terreno para a formação de outros PPGAS e de uma graduação em Ciências Sociais mais competente, porém ainda inconsistente em termos profissionais. ${ }^{11}$

${ }^{10}$ Como, por exemplo, a história e a geografia que nasceram na graduação não com o objetivo de pesquisa, mas de atuação de seus profissionais no ensino médio: "No Brasil, as ciências sociais são marcadas pela exigüidade de seu campo de atuação e a debilidade de seus vínculos com o sistema universitário. As ciências sociais mais tradicionais - a história e a geografia - se expandiram a partir dos unos 40 para atender ao magistério de nível médio, dentro de uma tradição francesa que não conseguiu se renovar antes de sucumbir à deterioração dramática que sofreu o ensino secundário no país [...]. As ciências sociais em sentido mais estrito se desenvolveram ao redor de pequenos grupos ou personalidades, para as quais o campo educacional e universitário, e a função educativa, nunca foi o mais importante, ou o mais significativo.” (Schwartzman, 1991, p. 55).

${ }^{11}$ O que acontece até os dias atuais. Ver Schwartzman (1991) sobre a necessidade da definição profissional do cientista social brasileiro através da conquista de um espaço social: "[...] proporcionar a este meio milhão de estudantes uma educação minimamente adequada seria o grande desafio para as ciências sociais brasileiras. Para que este desafio seja enfrentado, não basta que os professores e pesquisadores dos cursos de pós-graduação se disponham a ensinar nos cursos de graduação, como já ocorre em algumas de nossas universidades; é necessário ir muito mais além, a começar pelo questionamento da noção cômoda, mas equivocada, de que o conteúdo a ser ensinado nos cursos de graduação deve decorrer naturalmente dos interesses e preocupações dos pesquisadores e professores dos mestrados e doutorados [...]. A realidade é que as ciências humanas e sociais predominam em todos os sistemas de ensino superior em qualquer parte do mundo, entre outras razões pelo fato de que o número de atividades profissionais que requerem uso adequado da língua e conhecimentos gerais sobre a sociedade e o mundo contemporâneo é muito maior do que o das que requerem conhecimentos especializados e técnicos. Se os cientistas sociais não atenderem esse público, ninguém o fará” (p. 57) e o autor, ainda afirma a necessidade de aplicação, direcionando os seus cursos para os interesses das áreas mais técnicas: "Seria ingênuo acreditar que essa incorporação da missão universitária às ciências sociais possa ser fácil. Existem obstáculos de todo tipo, que incluem as limitações de formação dos cientistas sociais, o preconceito contra as áreas mais aplicadas e a própria resistência de outras disciplinas a uma tentativa de seu terreno por sociólogos, antropólogos e cientistas políticos. Não são, no entanto, obstáculos insuperáveis” (p. 58). 
A década de 70 foi um momento de consolidação dessa busca de fazer pesquisa antropológica no Brasil, que caminhou paralelamente à conjuntura de repressão política e ao desenvolvimento econômico do país.

As pesquisas na área das ciências sociais, que até então vinham sendo feitas, direcionaram. o pensamento antropológico. Por exemplo, a influência da tradição da antropologia britânica na década de 70 no Museu Nacional,12 Universidade de Brasília/UNB ${ }^{13}$ e Universidade Estadual de Campinas/ Unicamp,$^{14}$ contrastou radicalmente com a linha "sociologizante" presente nas pesquisas antropológicas do mesmo período na USP, ${ }^{15}$ dando a impressão, através da leitura de suas dissertações, de que a antropologia chegou "tardiamente” à Universidade de São Paulo. No entanto, no Museu Nacional as experimentações no estilo literário das etnografias, já estão presentes nos textos à partir da metade dos anos.70.

Portanto, apesar de inseridos dentro de um mesmo contexto nacional, os grupos de antropólogos formados e formadores dos PPGAS se constituíram e se desenvolveram de acordo com a singularidade específica à cada instituição.

A particularidade da institucionalização da antropologia no Museu Nacional - formadora do grupo de etnólogos nos cursos de especialização no início dos anos 60 - influenciou o Programa de Pós-Graduação em Antropologia Social na UNB pela transferência de parte deste grupo para

${ }^{12}$ Os primeiros cursos de especialização em antropologia no país foram criados no início dos anos 60 no Museu Nacional por Luiz de Castro Faria e Roberto Cardoso de Oliveira. Mas, o PPGAS/Museu Nacional iniciou-se em 1968 com a primeira turma de mestrado, após a reforma do ensino e a criação da pós-graduação segundo o modelo atual. Consultar sobre os museus no Brasil Souza Lima (1985, 1989), Castro Faria (1993) e Schwarcz $(1989,1993)$. Sobre a história do PPGAS/Museu Nacional Corrêa (1995) e Rubim (1996) entre outros.

13 A UNB foi criada em 1962 de acordo com a proposta de um grupo de intelectuais que tinha como liderança o professor Anísio Teixeira. Seu primeiro reitor foi o antropólogo Darcy Ribeiro que com o golpe militar em 1964 foi exilado. O PPGAS/UNB foi criado em 1972 por um grupo de antropólogos que se transferiram do Museu Nacional para Brasília, entre eles Roberto Cardoso de Oliveira, Roque de Barros Laraia e Júlio César Melatti. Ver sobre a história da UNB Ribeiro (1978a, 1978b, 1990), Fernandes (1990), Corrêa (1995) e Rubim (1996).

14 A Unicamp foi criada em 1966 e teve como primeiro reitor o professor Zeferino Vaz que encarregou o filósofo Fausto Castilho para organizar o Instituto de Filosofia e Ciências Humanas. Este, por sua vez, passou a responsabilidade de formação da área de antropologia para um jovem docente da USP: Antônio Augusto Arantes Neto que em 1971 deu início ao PPGAS/Unicamp juntamente com dois professores ingleses convidados por ele: Verena Martinez-Allier e Peter Fry. Ver sobre a história da Unicamp Lima (1989), Meneguel (1994) e Peña Flores (1995). Sobre o PPGAS/Unicamp consultar Corrêa (1995) e Rubim (1996).

${ }^{15}$ Mesmo a temática etnologia na década de 70 na USP - que é caracterizadora da disciplina no país -, totalizou somente duas dissertações das pesquisas institucionalmente consideradas como antropologia social. Para maiores detalhes consultar os anexos de Rubim (1996).

Horizontes Antropológicos, Porto Alegre, ano 3, n. 7, p. 97-128, nov. 1997 
Brasília. A grande maioria das pesquisas sobre sociedades tribais na década de 70 foram desenvolvidas no PPGAS em Brasília.

A Unicamp, que foi criada no interior paulista, iniciou o seu mestrado com dois antropólogos formados na tradição inglesa, Verena Martinez-Alier ${ }^{16}$ e Peter Fry, além de Antônio Augusto Arantes que, apesar de ter concluído o seu mestrado na USP em 1970, fez o seu doutorado em Cambridge na Inglaterra, sendo o responsável pela contratação de antropólogos com formação nesse mesmo país. Podemos dizer, então, que a antropologia na Unicamp nasceu ligada à tradição inglesa do pensamento antropológico.

De um modo geral, e devido a estas especificidades históricas, na UNB, Museu Nacional e Unicamp, ao contrário do que acontecia no mesmo período na USP, as pesquisas foram mais empiristas nos anos 70 e os autores mais citados foram os ingleses. O estruturalismo esteve também presente em todo esse período nas quatro instituições e, muitas vezes, ao lado do marxismo que apareceu como uma influência freqüente nas pesquisas, contribuindo por reforçar o pensamento europeu na antropologia brasileira.

$\mathrm{O}$ estruturalismo francês, que chegou ao pensamento social brasileiro no período anterior, fortaleceu-se na antropologia com algumas correntes formalistas ${ }^{17}$ como a etnociência e o decision-making, ${ }^{18}$ além das concepções de drama social, ritos de passagem, representações sociais ${ }^{19}$ que foram conceitos da antropologia inglesa recorrentes nas pesquisas do período. Claude LéviStrauss foi o autor praticamente obrigatório em todas as dissertações, com a exceção dos estudos sobre o campesinato mais influenciados pela tradição marxista através dos autores russos - Chayanov, Galeski e Tepich - e franceses - Althusser, Godelier, Balandier etc. Moacir Palmeira e Otávio Velho, foram os orientadores centrais neste campo até o início da década seguinte.

A antropologia feita na cidade se consolidou e as temáticas sobre a sociedade nacional ganharam importância e assumiram a liderança entre as pesquisas antropológicas no Brasil. No Rio de Janeiro, a antropologia urbana se desenvolveu em torno da problemática das classes médias e dos "desvios sociais" como o homossexualismo, a prostituição, os estilos de vida, as visões

\footnotetext{
16 Hoje Verena Stolcke.

17 Ver Woortmann (1993).

${ }_{18}$ Principalmente no PPGAS/UNB, quando estas correntes do pensamento antropológico foram introduzidas por Keneth Tylor no início dos anos 70.

19 Principalmente na Unicamp.
} 
de mundo etc. As orientações de Gilberto Velho foram decisivas nesse processo. Os autores americanos - Margareth Mead, Howard Becker, Irving Goffman por exemplo - foram citados quase que somente através das orientações feitas por Gilberto Velho e Roberto Da Matta. Foi também por meio dos orientandos de Da Matta que Cliffort Geertz e uma nova vertente do pensamento norte-americano foi introduzida no Museu Nacional já na década de $70 .{ }^{20}$ As dissertações orientadas por Da Matta também se utilizaram de autores franceses como Maurice Godelier, George Balandier, Michael Foucault e Lévi-Strauss.

Em São Paulo, os movimentos sociais urbanos foram privilegiados pelas análises da antropologia urbana, fundamentalmente através das orientações de Ruth Cardoso e Eunice Durham. Reflexo do lugar em que se encontravam as autoras, ${ }^{21}$ as pesquisas foram fortemente influenciadas pela problemática política, o que definiu a direção tomada pela antropologia urbana no país e aproximou ainda mais a antropologia em São Paulo da perspectiva sociológica predominante nas ciências sociais da USP.

Os estudos etnológicos na instituição, no entanto, devem ser analisados como um conjunto de pesquisas à parte. Seguindo uma tradição fundamentalmente antropológica e de acordo com as etnografias clássicas da disciplina, as dissertações sobre sociedades tribais não foram quantitativamente representativas no período, somando apenas 13,33\% da produção no PPGAS oficial da USP. ${ }^{22}$

Em Brasília, o tema central foi o estudo de grupos tribais, fortemente influenciados peio contexto político daquele momento e pela proximidade da antropologia da UNB com o governo central, ${ }^{23}$ além da tradição dos es-

${ }^{20}$ Lembro que a primeira publicação de $O$ ofício de etnólogo ou como ter "Anthropological Blues" foi de setembro de 1974 nas Comunicações do PPGAS. Neste texto. Da Matta discute a problemática da antropologia com uma clara influência do livro A interpretação das culturas de Clifford Geertz publicado no ano anterior nos Estados Unidos.

${ }^{21}$ No início dos anos 70, Ruth Cardoso e Eunice Durham transferiram-se para a área cie ciência política por discordância pessoal e política com o grupo de professores da área de antropologia. Conseqüentemente, grande parte dos antropólogos formados pelas duas docentes nas décadas de 70 e 80 possuem os seus títulos de mestres e doutores na área de ciência política. Este é o caso, por exemplo, de Mariza Corrêa, Guita Grin Debert, Tereza Caldeira, Carmem Cinira Macedo, Mauro William Barbosa de Almeida, Gilberto Velho, José Guilherme Cantor Magnani e Paula Montero entre outros.

${ }^{22}$ No mesmo período as dissertações em arqueologia foram de $53,33 \%$ do total.

${ }^{23}$ Até hoje esta proximidade se reflete na quantidade de mestres em antropologia social que ocupam funções públicas em órgãos governamentais como a Fundação Nacional do índio/FUNAI, a Procuradoria da República e o CNPq. Recentemente, o Hospital de Reabilitação Sarah Kubitcheck vem incentivando a contratação de antropólogos tanto pela matriz no Distrito Federal quanto em suas filiais em Salvador/ Bahia e São Luiz/Maranhão. 
tudos de populações indígenas implantado pelo grupo fundador do PPGAS. Foi um momento de grandes definições em relação à política indigenista no país, com a demarcação das terras indígenas, a criação do Parque Nacional do Xingu e a entrada em cena do índio como personagem e produtor de suas reivindicações através da criação de suas próprias entidades. ${ }^{24}$ Também os movimentos populares se organizaram e criaram entidades de apoio aos grupos indígenas como, por exemplo, a Associação Nacional de Apoio aos Índios/ANAI e a Pastoral do índio. ${ }^{25}$

Na Unicamp, os estudos dos moradores da periferia, aliado ao interesse mais geral pela história e pelos estudos sobre a situação da mulher de Verena Martinez-Alier direcionaram as temáticas escolhidas pela antropologia em Campinas, além da tradição inglesa dos primeiros professores, mais tarde reforçada pela contratação de José Luiz dos Santos, Maria Manuela Carneiro da Cunha e Luiz Mott. E significativo para a posição que os estudos de gênero ocupam hoje na história da antropologia campineira, que a primeira dissertação defendida na Unicamp possa ser incluída entre estas pesquisas. ${ }^{26}$ De um modo geral, e ao contrário das demais instituições estudadas, as escolhas temáticas das dissertações da Unicamp nos anos 70 não seguiram uma mesma direção. A pluralidade de temas foi a característica desses primeiros momentos que incluiu a antropologia urbana, a antropologia do campesinato, a antropologia da religião, as relações raciais, a etnologia, a família, a antropologia da saúde e os estudos de gênero. A ênfase nesta última temática já estava presente naquele momento ${ }^{27}$ e a contratação, um pouco mais tarde, de Mariza Corrêa reforçou ainda mais a tendência. Na Unicamp, as pesquisas na linha da antropologia do campesinato, seguiram na direção tomada por Otávio Velho no Museu Nacional nos anos 80, no que foram influenciadas pelas orientações teóricas seguidas por Verena Martinez-Alier, Antônio Augusto Arantes e Carlos Rodrigues Brandão.

${ }^{24}$ União Nacional Indígena/UNI.

${ }^{25}$ Organização ligada aos movimentos eclesiais de base da Igreja Católica no Brasil.

${ }^{26}$ Minha intenção original ao pensar este trabalho era investigar de que elementos se compõem as idéias sobre a mulher em nossa sociedade. Das notícias sobre o debate ocorrido no julgamento do marido e assassinato de Jô de Souza Lima, em Belo Horizonte, surgiu o projeto de observar a discussão dessas idéias através de processos jurídicos” (Corrêa, 1983, p. iv).

${ }^{27}$ Foram 23,52\% de dissertações concluídas na temática gênero contra 17,64\% em antropologia do campesinato e antropologia urbana. Houve também, $11,76 \%$ de pesquisas nas temáticas antropologia da religião e antropologia da saúde no mesmo período. 


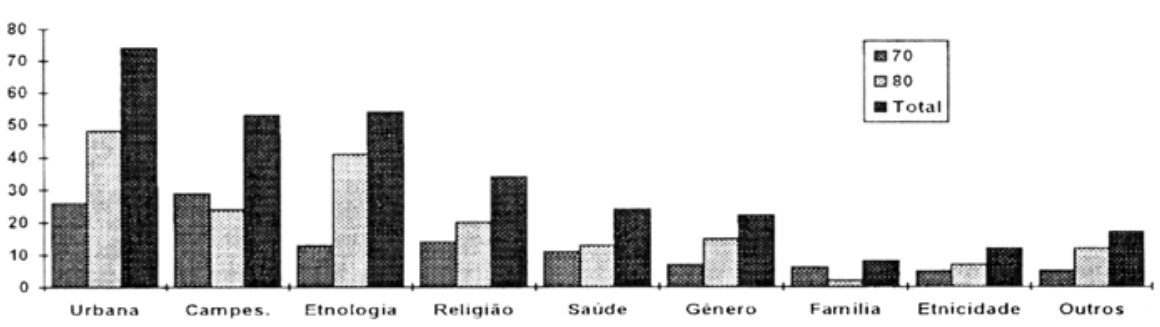

Neste contexto, o papel assumido pelas agencias internacionais como a Fundação Ford e a Fundação Fulbright, além de instituições nacionais de fomento à pesquisa como o CNPq, CAPES, Financiadora de Estudos e Projetos/ FINEP, Fundação de Amparo a Pesquisa no Estado de São Paulo/FAPESP foram imprescindíveis ao desenvolvimento da pesquisa antropológica no país. No momento de implantação dos primeiros PPGAS, CAPES e CNPq assumiram a liderança no apoio às dissertações em antropologia social, seguidas pela Fundação Ford e FAPESP, o que transformou a tendência de uma concepção diferenciada em relação às ciências sociais, enquanto um campo produtor de pesquisa científica no país, quando comparado às ciências exatas e biológicas por parte destes órgãos, apontada por Forjaz (1989) no período anterior à era da pós-graduação que tinha como consequência uma quantidade menor de verbas.

Foi uma época rica para a nossa disciplina em termos da quantidade do que se produziu na pós-graduação e em relação à pluralidade das escolhas temáticas. Rompeu-se definitivamente nesse período com uma concepção da disciplina exclusivamente ligada aos estudos étnicos. Os antropólogos brasileiros profissionalizaram-se, as temáticas diversificaram-se, o diálogo com o exterior intensificou-se e as trocas de experiências internas transformaram-se qualitativamente através do reaparecimento, na segunda metade da década, de associações profissionais como a $\mathrm{ABA}^{28}$ e a criação de outras como a Associação Nacional de Pós-Graduação em Ciências Sociais/ANPOCS.

${ }^{28}$ As reuniões da ABA foram esvaziadas a partir de 1964. No período de 12 a 14 de dezembro de 1974 foi realizada a IX reunião da Associação Brasileira de Antropologia em Florianópolis, sendo eleito presidente o professor Manuel Diegués Junior. Os sócios eram, nessa época, quase duzentos. Hoje somos aproximadamente 725 membros entre sócios efetivos (no mínimo com o título de mestre) e estudantes (ABA, 1994/1995). 
Além da ANPOCS, em 1977 foi criado o doutorado em antropologia social do Museu Nacional e fundado o Anuário Antropológico na UNB. A Revista de Antropologia que tinha deixado de ser publicada no início dos anos 70, retornou em 1978 ainda sob a direção do professor Egon Schaden, ${ }^{29}$ já aposentado, e com apoio institucional do Departamento de Ciências Sociais da Faculdade de Filosofia, Letras e Ciências Humanas/FFLCH da USP. Outros programas de pós-graduações, fora do eixo Rio-São Paulo, começaram a ser implantados também nessa fase: Universidade Federal do Rio Grande do Sul/ UFRGS $^{30}$ e Universidade Federal de Pernambuco/UFPE. ${ }^{31}$

A década de 70 foi plural, no que se refere à produção de várias linhas de pesquisa, no aprofundamento das temáticas que nas décadas anteriores vinham sendo desenvolvidas e, enfim, na busca de um caminho próprio ao fazer/ pensar antropológico em nossa realidade específica. A dinâmica do campo da antropologia social nesse momento, contrastou com a falta de liberdade mais geral e a crise econômica enfrentada pela sociedade nacional. Como afirmaram Otávio Velho (1980), Eunice Durham (1986) e Ruth Cardoso (1986), essa produção - diversificada tematicamente e quantitativamente superior em relação a tudo o que foi produzido até então - não foi acompanhada de uma discussão à respeito do que se fazia no campo da antropologia social.

O final da década de 70 marcou o início da autoconsciência da antropologia brasileira, do pensamento crítico em relação ao nosso lugar como intelectuais e cidadãos neste país. Começou-se a perceber que para produzir conhecimento criativo e significativo não bastava fazer ciência, mas era preciso também que se pensasse e se questionasse sobre o quê e como o conhecimento era

${ }^{29}$ Ora, no quarto de século decorrido desde a fundação da revista, iniciativa na época tida como temerária ou audaciosa, mudou bastante o panorama das atividades antropológicas em nosso País. Éramos então um punhado de estudiosos que acreditavam na necessidade de promover o ensino e a pesquisa da Antropologia segundo métodos e padrões modernos, superando os entraves do amadorismo. O estudo e a pesquisa dos problemas antropológicos, que então existiam em apenas uma ou outra instituição, fazem parte agora de dezenas de Universidades e Faculdades pelo Brasil afora. Contamos com toda uma nova geração de antropólogos competentes, cujos trabalhos, muito deles de alto nível, já não deixam lugar a dúvidas quanto ao vigor que hoje marca a Antropologia em nossa terra” (Schaden, 1984, p. 1).

${ }^{30}$ Na UFRGS em 1974 foi criado o Curso de Especialização em Antropologia Social; em 1979, o Mestrado em Ciências Sociais com concentração nas áreas de antropologia, sociologia e ciência política, que em 1986 se separou em três programas diferenciados. O Doutorado em Antropologia Social foi criado no início dos anos 90 (entrevista com o professor Rubem Oliven em 10 de abril de 1995, UFRJ).

31 No início dos anos 70 foi criado na UFPE o Mestrado Integrado em Sociologia e Economia; em 1976, a Especialização em Antropologia Social e em 1977 o Mestrado em Antropologia Social (entrevista com o professor Russel Parry-Scott em 11 de abril de 1995, UFRJ).

Horizontes Antropológicos, Porto Alegre, ano 3, n. 7, p. 97-128, nov. 1997 
produzido. Iniciou-se um saudável processo de diferenciação teórica e prática que, conseqüentemente, fez com que se explicitassem divergências. ${ }^{32}$

Em relação ao contexto mais amplo, esse foi um momento extremamente fértil em termos de discussão e produção do pensamento social brasileiro. A anistia política em 1979 e a abertura "lenta, gradual e segura”, criou um clima de liberdade e agitação intelectual; os movimentos sociais começaram a reaparecer no cenário político nacional; novas idéias circularam rapidamente e o diálogo interno e externo se intensificou; o interesse por novas temáticas era visível, particularmente na antropologia social, onde começou-se a produzir pesquisas sobre uma parcela da população que até então encontrava-se marginalizada social e/ou politicamente: favelados, meninos de rua, operariado etc. (Cardoso, 1986; Durham, 1986).

Nos anos 80, a crise econômica voltou a fazer parte de nosso dia-a-dia ao mesmo tempo em que o processo democrático acelerou-se. A campanha pelas eleições diretas para Presidente da República ganhou as ruas.

A influência da antropologia interpretativa - a problemática do projeto da antropologia enquanto ciência e do trabalho de campo - começou a ser discutida nas dissertações. O espaço preenchido por Lévi-Strauss no período anterior foi ocupado por Clifford Geertz, tornando o autor referência quase obrigatória na década de 80 .

A exaustão do pensamento estruturalista começou a ser percebida nas ciências sociais, na história e na filosofia. A antropologia norte-americana voltou a influenciar a disciplina no Brasil. Primeiramente através do interpretativismo de Clifford Geertz e, mais tarde, com os chamados autores pós-modernos. Nesse período, a hermenêutica foi uma tendência quase hegemônica nas dissertações da UNB, um pouco menos na Unicamp e no Museu Nacional, praticamente inexistindo na USP que começou naquele momento a se "antropologizar". ${ }^{33}$ As orientações das professoras Thekla Hartmann e Lux

32 Consultar capítulos sobre o Museu Nacional e USP em Rubim (1996).

${ }_{33}$ Mesmo assim, nos anos 80 ainda foram concluídas dissertações no campo da antropologia social que explicitamente se utilizavam do referencial teórico denominado pelos seus autores de "Escola Sociológica de São Paulo”: “Tal qual está projetada, esta pesquisa situa-se metodológica e teoricamente na linha de estudos sociológicos da chamada Escola Sociológica de São Paulo, com suas discussões sobre raça e classe e onde estão situados autores como: Florestou Fernandes [...]; Roger Bastide [...]; Octávio Ianni [...] e Fernando Henrique Cardoso [...]. Porém, apresenta um compromisso teórico, metodológico e técnico com a Antropologia na medida em que incorpora à discussão os tópicos ligados à representação e a identidade étnica, o que faz. com que a discussão passe obrigatoriamente por reflexões ligadas à cultura, 
Vidal, foram decisivas ${ }^{34}$ na formação de um grupo de etnólogos na USP. Mais tarde este grupo foi reforçado com a contratação de uma ex-aluna, Dominique Gallois, e de Maria Manuela Carneiro da Cunha, aluna egressa e docente da Unicamp. Na década de 80, as pesquisas sobre as sociedades tribais somaram $26,92 \%$ do total oficial em antropologia social. ${ }^{35} \mathrm{Na}$ contagem geral das quatro instituições e nas duas décadas consideradas, a USP foi a que mais pesquisas acumulou em etnologia: 29,09\%. ${ }^{36}$

Nesse período, no Museu Nacional, iniciou-se um processo de desaceleramento das pesquisas na temática da antropologia do campesinato. Moacir Palmeira e Otávio Velho afastaram-se das orientações, cedendo lugar a professores mais novos como Lygia Sigaud, José Sérgio Leite Lopes e Afrânio Garcia Jr.

Ao mesmo tempo os estudos sobre os grupos urbanos se multiplicaram nos quatro PPGAS, tornando-se a grande maioria no cômputo geral das décadas de 70 e 80.

$\mathrm{Na} \mathrm{UNB}$, as pesquisas sobre as sociedades indígenas continuaram na mesma direção do período anterior: os contatos com a sociedade nacional e a política indigenista foram enfatizados ainda mais.

No Museu Nacional, com a contratação de um grupo de etnólogos no fim do período anterior - Anthony Seeger, Eduardo Viveiros de Castro e João Pacheco de Oliveira -, intensificaram-se as pesquisas referentes às sociedades ameríndias do Brasil, além das orientações em andamento de Roberto Da Matta em etnologia.

Também a contratação de novos antropólogos na Unicamp, reforçou temáticas que já vinham sendo desenvolvidas como os estudos feministas ${ }^{37} \mathrm{e}$

à identidade cultural e à manipulação da etnicidade. Neste sentido, também espera-se contribuir para a análise de outras dimensões do comportamento político-eleitoral, estudo até então à cargo da Sociologia e da Ciência Política que, ao utilizarem principalmente técnicas quantitativas, deslocam para um plano secundário o conjunto de representações e valores que os indivíduos têm, o que em certa medida, limita a compreensão global do fenômeno em análise” (Valente, 1984, p. 4-5).

${ }^{34}$ Ambas orientaram $11,11 \%$ do total da produção em etnologia nas décadas de 70 e 80 entre as quatro instituições consideradas.

${ }^{35}$ Contra 32,69\% na sub-área de arqueologia.

${ }^{36}$ Contra 28,81\% na UNB, 12,21\% no Museu Nacional e 9,09\% na Unicamp para o mesmo período. Se formos considerar os números oficiais da USP, isto é, num conjunto de 67 dissertações onde estão incluídas as dissertações em arqueologia e excluídas as dissertações orientadas por Ruth Cardoso e Eunice Durham, a etnologia somou $23,88 \%$ contra $37,31 \%$ de pesquisas em Arqueologia para o mesmo período.

${ }^{37}$ Hoje denominados estudos de gênero. 
de cultura popular. De um modo geral, as dissertações orientadas por Antônio Augusto Arantes e Carlos Rodrigues Brandão em antropologia do campesinato, antropologia da saúde, antropologia da religião e antropologia urbana foram permeadas pela problemática da cultura popular.

Nos anos 80, foram criados o doutorado em antropologia social da UNB (1981) e o doutorado em ciências sociais na Unicamp (1984). A produção no mestrado cresceu ainda mais nos anos 80 com exceção da UNB, onde houve um declínio que se acentuou no final da década. ${ }^{38}$

Anteriormente à era da pós-graduação, podemos dizer que as temáticas desenvolvidas ${ }^{39}$ se restringiam praticamente a duas: etnologia ${ }^{40}$ e minorias étnicas. ${ }^{41} \mathrm{~A}$ institucionalização dos PPGAS inaugurou um período plural em relação ao objeto de estudo da antropologia social. Não somente as temáticas consideradas tradicionais na disciplina se intensificaram - por exemplo, uma tendência cada vez maior no crescimento da etnologia - como várias outras linhas de pesquisas emergiram ${ }^{42}$ e ganharam espaço no campo da antropologia brasileira: religião, saúde, desvios sociais etc. A subtemática pesca, no entanto, praticamente desapareceu nos anos 80 e 90 . Hoje podemos dizer que quase tudo é possível de ser estudado antropologicamente. ${ }^{43}$

Esta tem sido a característica central da antropologia social no Brasil, isto é, a capacidade singular da disciplina em captar como temática os aspectos polêmicos de nossa realidade. Foi assim no passado com os índios, negros e minorias étnicas. Acontece ainda em nossos dias com as discussões sobre AIDS, ética na política, empregadas domésticas etc. Conseqüentemente, o objeto de estudo da disciplina possui a capacidade, tanto de se transformar no decorrer do tempo, quanto o de conseguir ser plural em um determinado momento histórico através da diversidade de seus temas. Muito do sucesso

\footnotetext{
${ }^{38}$ É interessante notar que nas duas instituições onde concentraram-se a maioria das pesquisas etnológicas - USP e UNB - houve uma redução quantitativa da temática na segunda metade da década de 80.

39 Os estudos de comunidade (Wagley, 1953; Willems, 1947, etc.) não podem ser incluídos nesta tradição pois ficaram restritos a um determinado período - final da década de 40 e início dos anos 50 - sem contudo se tornar uma linha de pesquisa recorrente na antropologia brasileira.

${ }^{40}$ Eduardo Galvão, Darcy Ribeiro, Florestan Fernandes e mais recentemente na década de 60, Roberto Cardoso de Oliveira.

41 Tradição que remonta a Nina Rodrigues (Corrêa, 1982), Arthur Ramos (Azeredo, 1986) e nos anos 60, João Baptista Borges Pereira que basicamente elegeu o negro como objeto central de análise.

42 Algumas temáticas se consolidaram no tempo, outras diminuíram o ritmo da produção e uma parte delas praticamente desapareceu nos anos 80 .

${ }^{43}$ Ver o crescimento proporcional do item OUTROS na classificação temática das dissertações.
} 
alcançado pela disciplina entre os cientistas sociais e o público mais geral, está relacionado a esta capacidade "plástica" da antropologia social em se adaptar a diferentes espaços nacionais e diferentes momentos históricos. A vocação "pluralista" das ciências sociais do passado que dominava as primeiras gerações de cientistas sociais, segundo Antônio Cândido (apud Peirano, 1992, p. 45), parece ter sido herdada e capitalizada pela Antropologia Social contemporânea no Brasil e criativamente ampliada. E um pluralismo saudável e enriquecedor do pensamento antropológico e que levou à afirmação pejorativa por parte de Castro Faria:

Se a antropologia social não se dissolveu na sociologia ao promover seu afastamento das disciplinas que compunham o espectro da antropologia geral nem por isso criou uma identidade própria. Ao contrário, a meu ver, ela se tornou apenas uma espécie de abrigo, ou recolhimento para desamparados da sociologia, da economia, da história, da ciência política, e até da medicina, do direito, da arquitetura, isto lhe dá o direito de insinuar-se em todas essas áreas. O qualificativo de antropologia insinuante fica-lhe bem. (Castro Faria, 1993, p. 99).

Uma das características da antropologia social dos anos 90 no Brasil tem sido a sua preocupação consigo mesma. Quem somos nós e o que temos feito de concreto, são perguntas recorrentes entre os antropólogos brasileiros. Pesquisas sobre esta temática tem se multiplicado e hoje podemos dizer que se transformou em uma linha de pesquisa da disciplina presente em quase todas as instituições e em vários Grupos de Trabalho, Seminários e Mesas Redondas que vêm acontecendo em nossos encontros nacionais e regionais. A preocupação com a reconstrução de nossa história e com a busca da compreensão de nossas tradições teóricas é uma constante, tanto entre os antropólogos da Universidade Federal do Rio Grande do Sul, ${ }^{44}$ quanto na USP ${ }^{45}$ e Unicamp, ${ }^{46}$ como também em Pernambuco, Rio de Janeiro e no Museu Emílio Goeldi no Pará. O lugar ocupado pela antropologia da Unicamp, neste contexto,

44 Ruben Oliven (entrevista) afirma que existe um esforço em sua instituição na reconstrução do pensamento antropológico gaúcho.

45 Neste sentido é que entendemos os esforços do professor José Guilherme Cantor Magnani que como coordenador da pós-graduação em antropologia, empenhou-se no mapeamento do corpo docente e discente e suas respectivas pesquisas desenvolvidas na instituição.

46 O Projeto História da Antropologia no Brasil coordenado pela professora Mariza Corrêa tem contribuído neste sentido. 
tem sido de fundamental importância. E nessa instituição onde encontramos pesquisas sobre a história da disciplina ${ }^{47}$ e da trajetória intelectual de autores como Roquete Pinto e Charles Wagley, além dos arquivos de Donald Pierson e Roberto Cardoso de Oliveira, no âmbito do Projeto História da Antropologia no Brasil.

Existe hoje um contexto favorável no campo antropológico e das ciências sociais no país, que possibilita e até mesmo incentiva a discussão. A tendência cada vez maior por parte de antropólogos formados no Brasil em pesquisar fora do país, ${ }^{48}$ demonstra não somente um amadurecimento da antropologia brasileira como a afirmação de um estilo nosso de fazer pesquisa, escolher temáticas e levantar problemas. Mas, com certeza, também fazemos parte da tradição da antropologia mundial, preservando tradições, recorrendo aos seus clássicos e transmitindo e compartilhando essa história mais abrangente.

\section{Antropologia brasileira: uma pluralidade de pluralidades}

O PPGAS/Museu Nacional nasceu e se desenvolveu em função dos grandes projetos realizados por suas equipes de professores e financiados por diferentes agências. Esta foi a marca da antropologia social no Rio de Janeiro, que em função da proposta coletiva da maioria de suas pesquisas conseguiu uma eficiência exemplar, e não deve ser somente explicada pela sua existência num período mais longo de tempo: desde a primeira defesa de

47 Somente a UNB possui uma dissertação sobre a história da antropologia, particularmente do PPGAS de Brasília (Mendoza, 1994).

48 Temos os seguintes pesquisadores que fazem ou fizeram pesquisas no exterior: Ruy Coelho (1960), Os karaíb negros de Honduras; George de Cerqueira Zarur (1975), Seafood gatherers in mullet springs: economic rationality and the social system; Luis Tarlei de Aragão (1980), Tradition et modernisme dans la Ville Nouvelle de St. Quentin-en-Yvelines: utilisation des méthodes anthropologiques dans l'étude d'une Ville Nouvelle; Maria Manuela Liege Carneiro da Cunha (1985), Negros, estrangeiros: os escravos libertos e sua volta à África; Leonardo Fígoli (1990), A ciência sob o olhar etnográfico - estudo da antropologia argentina; Mariza Peirano (1991), Uma antropologia no plural - três experiências contemporâneas; Claudia Fonseca (1993), Crime, corps, drame et humour: famile et quotidien dans la culture populaire; Stephen Baines (1993), Primeiras impressões sobre a etnologia indígena na Austrália; Federico Neiburg (1993), A invenção do peronismo e a constituição das ciências sociais na Argentina; Gustavo Lins Ribeiro (1994), Transnational capitalism and hidropolitics in Argentina; Celso Azzan Junior (1995), Fragmentos de uma disciplina: a antropología do Québec vista de dentro; Wilson Trajano Filho (tese de doutorado em andamento na Guiné-Bissau); Marta Tepd (tese de doutorado em andamento em Israel); Guilhermo Raul Ruben (pesquisa em andamento na Argentina e Canadá); Roberto Cardoso de Oliveira (pesquisa em andamento na Espanha).

Horizontes Antropológicos, Porto Alegre, ano 3, n. 7, p. 97-128, nov. 1997 
mestrado em 1970, a primeira dissertação de um PPGAS no país, até o final do período estudado aqui. E esta a singularidade que distingue as pesquisas no Museu Nacional e que proporciona um sentimento de pertencimento entre seus autores.

O espaço de estudo que os alunos possuem no PPGAS/UNB, facilita encontros, críticas e discussões coletivas entre professores e alunos. Proporciona um trabalho coletivo por parte do corpo discente e influencia a formação de grupos de pesquisas que se concentram em determinadas temáticas. ${ }^{49}$ Este “detalhe” está relacionado com as condições do trabalho intelectual e presente nos agradecimentos das dissertações, nas auto-referências e, portanto, na socialização da produção do conhecimento e no seu aprendizado em Brasília. A existência do espaço criou práticas coletivas que possibilitaram a construção de uma consciência de identidade, de história e de tradições construídas em conjunto. Uma história compartilhada não somente pelos que ensinam, mas também entre aqueles que aprendem.

As pesquisas feitas na Unicamp caracterizam-se pelo estilo visual das etnografias e pelo diálogo entre pesquisador e pesquisado, presente na maioria das dissertações desde o início do PPGAS. ${ }^{50}$ Mesmo que não explicitamente, a relação de proximidade e do que hoje se convencionou chamar de "diálogo” transparece na maioria destas pesquisas. Nas demais instituições, principalmente na UNB, existe um fluxo temático que parece seguir quase sempre numa mesma direção. Ao contrário, a Unicamp é mais plural em relação a sua produção e às temáticas desenvolvidas. Talvez pela especificidade do contato constante e diário com filósofos, sociólogos, cientistas políticos e historiadores. Esta "aparente” diluição das diferentes áreas das ciências humanas, contribui também com uma interdisciplinaridade mais intensa e um diálogo maior entre as disciplinas. ${ }^{51}$

Na USP, os orientadores e suas temáticas foram os referenciais para as escolhas feitas pelo corpo discente. Portanto, os orientandos de Ruth Cardoso e Eunice Durham, por exemplo, se consideram e são considerados entre os

49 Foi assim com o grupo composto por Tavares (1975), Peirano (1975) e Maranhão (1975) que foram estudar os pescadores de Icaraí, Ceará, no início dos anos 70; foi assim na década seguinte também com as pesquisas de Lazarin (1981), Romano (1982) e Fígoli (1982) que pesquisaram os índios citadinos em Manaus, Amazonas.

${ }^{50}$ O que Geertz (1989) diz ser a característica da antropologia inglesa.

51 Não é por acaso, portanto, que um doutorado em ciência sociais tenha sido criado justamente na Unicamp. 
cientistas sociais brasileiros como antropólogos, mesmo com os seus diplomas exibindo o título de cientistas políticos. ${ }^{52}$ Os arqueólogos e os etnólogos compõem um outro grupo com as suas respectivas singularidades; os orientandos de João Baptista Borges Pereira - nas temáticas educação e etnicidade - formam um grupo diferenciado. Nos anos 90, a situação começa a se transformar, muito em função, no meu entender, do novo formato que o Departamento de Antropologia Social vem assumindo com a contratação de uma nova geração de professores ${ }^{53}$ e a conseqüente abertura do leque temático na instituição.

Ou seja, o formato da organização dos respectivos espaços institucionais acabaram por influenciar as suas produções. No entanto, e apesar de suas singularidades, fica claro na história dessas quatro instituições que é impossível falar de uma delas sem se referir às demais. Mesmo a antropologia social em Campinas, que aparentemente nasceu mais “independente”, deixou explícito na sua trajetória e na de seus principais personagens, que o PPGAS da Unicamp se desenvolveu em função das crises e discussões teóricas travadas no final da década de 60 na USP. As escolhas feitas por Antônio Augusto Arantes, não foram casuais naquele momento e estavam comprometidas com as escolhas teóricas do autor no contexto antropológico existente na USP no final dos anos $60,{ }^{54}$ quando pertenceu ao grupo de professores formados por Ruth Cardoso, Eunice Durham entre outros e que optou pela antropologia social inglesa. Neste país, Arantes escolheu fazer o seu doutorado e encontrou Verena Martinez-Allier e Peter Fry. Um pouco mais tarde, parte dos que se tornaram seus professores na segunda e terceira geração intelectual, também foram formados de acordo com determinada perspectiva da antropologia na FFLCH/USP.

De um modo geral, a antropologia na USP seguiu a tradição racionalista francesa. O PPGAS do Museu Nacional herdou muito desta tradição através da influência de um de seus personagens, socializado intelectualmente no ambiente das ciências sociais paulista, mas também pela contratação de Moacir Palmeira, que se formou na própria França. Contudo, o Museu Nacional também recebeu influências da tradição da antropologia social inglesa através

52 Ou de cientistas sociais na área de ciência política, o que acontecia antes do desmembramento do Departamento de Ciências Sociais em 1986.

53 Como, por exemplo, Lilia Schwarcz, José Guilherme Cantor Magnani, Margarida Maria Moura Dominique Gallois, etc.

54 Para maiores detalhes consultar os capítulos sobre a USP e a Unicamp em Rubim (1996). 
de Otávio Velho (Manchester, Inglaterra) e do próprio Roberto Cardoso de Oliveira que naquele momento esteve muito próximo à tradição britânica. A tradição norte-americana esteve presente através de Gilberto Velho (Austin, EUA) e Roberto Da Matta (Harvard, EUA).

Do grupo de antropólogos do Museu Nacional nasceu o PPGAS da UNB, que tinha parte de seus mais eminentes representantes doutorados pela Universidade de São Paulo: Roque de Barros Laraia, Júlio César Melatti e o próprio Roberto Cardoso de Oliveira. Por outro lado, o Programa em Brasília foi também influenciado pela antropologia norte-americana através, principalmente, de Alcida Rita Ramos (Wisconsin, EUA) e de Kenneth Ian Tylor (Wisconsin, EUA).

A USP, queiramos ou não, foi a origem da maioria de nossos professores e, em última instância, dos professores daqueles que atualmente são nossos professores.

Hoje a antropologia no Brasil possui algumas características que a tornam diferente da antropologia praticada em outros países. A principal delas é a de ser uma antropologia sociocultural, ou seja, não existe uma tradição em nosso país de se pensar em termos de antropologia física, ${ }^{55}$ por exemplo. Os esforços existentes neste sentido são quase sempre consequência de iniciativas individuais e só ocorrem em algumas poucas instituições do país. A arqueologia ${ }^{56}$ e a lingüística seguem trajetórias específicas e até certo ponto “independentes” das discussões teóricas e problemas levantados pelo campo da antropologia no Brasil. ${ }^{57}$

55 Para Lux Vidal (entrevista em 27 de março de 1996, São Paulo), a antropologia física evoluiu tanto nos últimos anos, que hoje necessita de laboratórios de genética para as suas pesquisas, o que fez com que a disciplina se desenvolvesse melhor na biologia e na própria genética.

${ }^{56}$ Na Faculdade Estácio de Sá no Rio de Janeiro também existe um curso de graduação em arqueologia. Segundo a professora Lux Vidal (entrevista), a arqueologia no Brasil está se desenvolvendo muito em torno de grandes polêmicas como, por exemplo, a datação do homem americano e brasileiro. No entanto, é uma disciplina complicada no país, porque as nossas populações ameríndias não chegaram a ser Civilizações-Estados como na Meso-América e os arqueólogos trabalham com pouco material em consequência da acidez do solo, o que torna os testemunhos perecíveis e pouco preservados.

57 Se a antropologia tem a capacidade de “insinuar-se” em várias outras áreas, como afirma Castro Faria (1993) já citado, no que concordo, é porque a disciplina conquistou esta legitimidade pela singularidade de seu “olhar”, pela capacidade de percepção da especificidade em diferentes campos do conhecimento. Talvez, por este mesmo motivo, mais que as outras disciplinas sociais, a antropologia tem sido requisitada na graduação tanto na área médica quanto na área de comunicações, letras, artes, biologia e até na arquitetura.

Horizontes Antropológicos, Porto Alegre, ano 3, n. 7, p. 97-128, nov. 1997 
O cosmopolitismo ${ }^{58}$ presente em grande parte das dissertações, influenciou a sua produção e contribuiu na construção de uma visão original e dinâmica do pensamento antropológico entre nós. Neste sentido, foram fundamentais o estilo etnográfico "visual” herdado da antropologia social emergente no início dos PPGAS, principalmente através da produção da Unicamp, mas também do Museu Nacional e da UNB. Também o interpretativismo de Clifford Geertz que, quase na mesma época, começou a influenciar a antropologia, inicialmente no Museu Nacional e mais tarde nas demais instituições, inclusive a USP nos anos 80; e do estruturalismo que atravessou a quase-totalidade desta produção nas duas décadas consideradas. Uma concepção de militância política $^{59}$ através do marxismo foi incorporada pela prática da pesquisa de campo. Somou-se a isso a crítica da antropologia pós-moderna dos anos 80 e temos, então, a antropologia social no Brasil dos anos 90.

Atualmente, a antropologia social não é somente a constatação de que “eu” estive lá e vi, o que Geertz (1989) já afirmou e confirmou; mais que isto, é: "eu” vivi o "outro", tentei sentir o que ele sentia sem abandonar a minha própria perspectiva e, finalmente, consegui compreende-lo objetivamente através do distanciamento e da consciência crítica - e subjetivamente - através da vivência. Agora, este "outro", antes estranho e desconhecido, faz parte da minha própria história de vida e conseqüentemente de minha subjetividade também. E é esta capacidade de transmitir o "outro" através de nós mesmos, textualizando-o, que é também uma das principais características do texto antropológico.

Mas, para melhor entendermos isso nos termos de nossa disciplina, cabe ainda algum esclarecimento sobre a questão desse sentido alcançado pela compreensão. Diria, portanto, que enquanto a explicação dá conta daquelas dimensões do real

58 Ao contrário do que afirma Fábio Wanderley Reis (1991, p. 31): “[...] o fato de que estaremos lendo o que se produz, internacionalmente (coisa que, afinal, fazemos avidamente em nosso provincianismo dependente) [...]”, as dissertações em antropologia no Brasil utilizam-se de várias tradições da disciplina. Uma constatação diferente daquela que Reynoso (1991) diz acontecer com os autores norte-americanos por referirem-se quase que exclusivamente a si mesmos em suas pesquisas.

59 Ou “populismo” segundo Otávio Velho (1980). Para Peirano (1982, p. 38), “[...] se as diversas conjunturas com que o antropólogo se defronta o fazem repensar a teoria sociológica clássica ocidental, isto - que é a força, da antropologia - pode tomar-se a sua fraqueza, se apenas o exótico é privilegiado. No Brasil, o efeito pernicioso aumenta quando, num pretenso engajamento político, tentamos estranhar e resgatar camadas oprimidas da população e acabamos muitas vezes fazendo-lhes o desfavor de revelá-las, por exemplo, nos tais relatos entediantes sobre as mulheres da periferia urbana.” 
susceptíveis de tratamento metódico (por métodos funcionais e/ou estruturais, por exemplo), a compreensão capta aquilo que Ricoeur chama de "excedente de sentido" (surcroît de sens). Não é difícil para nós apreender, mesmo intuitivamente, o que significa esse excesso de sentido, desde que consideremos que tudo aquilo possuidor de alguma significação que seja irredutível a métodos, pode ser de alguma maneira recuperado pela via da compreensão. Aliás, é por aí que nos reencontramos com a distinção gadameriana entre "verdade" e "método", ${ }^{60}$ segundo a qual toda a "verdade" (ou simplesmente a veracidade) não se alcança pelo caminho exclusivo do método. Esse algo mais que lhe escapa não só pode, mas deve ser alcançado pela via da compreensão. (Cardoso de Oliveira, 1994, p. 24-25).

\section{A antropologia social na era da pós-graduação}

Como afirmou Peirano (1981, p. 227) "[...] the nation was central unit of anlysis for most of the authors considered”. Ou seja, o desenvolvimento da antropologia no Brasil está relacionado à compreensão do país e à construção de uma identidade nacional. O caminho do reconhecimento do território nacional foi a direção que se impôs à antropologia brasileira. ${ }^{61}$ De um modo geral, existe entre nós uma obsessão cultural pelo tema da identidade entre as ciências humanas. A antropologia não fugiu à regra. A sua trajetória demonstra um esforço pela compreensão de quem somos nós e de como nos distribuímos neste espaço diversificado que é o país. Contudo, podemos afirmar que, não somente as temáticas são escolhidas em função da cidadania de seus autores, mas também em função de suas trajetórias dentro de uma determinada tradição e, portanto, de acordo com as especificidades encontradas em cada instituição que, por sua vez, possuem uma história estreitamente ligada às trajetórias de seus docentes. Assim como estamos ligados teoricamente aos clássicos da antropologia - Malinowski, Evans-Pritchard, Victor Turner, LéviStrauss, Clifford Geertz etc. -, também fazemos parte dos diferentes grupos formadores dos PPG AS. Seguimos, na maioria das vezes, as "linhagens" sedimentadas em nossa tradição.

60 Podemos fazer a mesma pergunta em relação à antropologia: o importante não é saber se é “ciência”, arte ou "literatura"; fundamental é entender que é um tipo de conhecimento relevante e indispensável no mundo atual.

61 Por analogia, a antropologia social fez com o Brasil na era da pós-graduação, o que o Marechal Rondon tinha feito no início do século: “reconheceu” o território e implantou marcos. 
Nos anos 30, o mito das três raças formadora do país influenciou a trajetória da disciplina. Foram pesquisas sobre os segmentos de nossa população: grupos tribais, negros e imigrantes. As análises tinham como concepção teórica a idéia da harmonia interna dos grupos e, portanto, a análise proporcionava uma compreensão desses segmentos sociais como grupos isolados da sociedade nacional.

A antropologia social no Brasil escolheu como objeto de estudo os marginalizados - no sentido social, político e econômico -, o que contribuiu para a direção temática e teórica da disciplina e com os rumos do pensamento social brasileiro.

A teoria da fricção interétnica de Roberto Cardoso de Oliveira se desenvolveu na década de 60 e se "popularizou" na academia nos anos 70, com uma perspectiva diferente das pesquisas que até então vinham sendo feitas. Ao contrário do que afirmava a teoria da democracia racial de Gilberto Freyre, do relacionamento entre culturas/sociedades diferentes como um processo absorvido sem grandes crises, Roberto Cardoso de Oliveira enfatizou o conflito de nossa formação cultural, contemplando as necessárias relações de poder existentes entre brancos, negros e índios no Brasil.

[...] essa triangulação étnica, pela qual se arma geometricamente a fábula das três raças, tornou-se uma ideologia dominante, abrangente, capaz de permear a visão do povo, dos intelectuais, dos políticos e dos acadêmicos de esquerda e de direita, uns e outros gritando pela mestiçagem e se utilizando do "branco", do "negro" e do "índio" como as unidades básicas através das quais se realiza a exploração ou a redenção das massas. O que parece ter ocorrido no caso brasileiro foi uma junção ideológica básica entre um sistema hierarquizado real, concreto e historicamente dado e a sua legitimação ideológica num plano muito profundo. (Da Matta, 1987, p. 63).

A teoria da fricção interétnica foi o contraponto do mito da democracia racial no país, que nos anos 60 já não conseguia explicar satisfatoriamente - nem cientificamente, nem em relação ao senso comum - a realidade vivenciada. O contexto social existente nesse período, com uma qualidade diferente dos anos 20 e 30, proporcionou ao pensamento social brasileiro o desenvolvimento de uma alternativa ao que vinha sendo afirmado até então.

As transformações sociais, econômicas e políticas que estavam ocorrendo possibilitaram esta transformação. Anteriormente, foram as ciências 
sociais através de seu principal teórico, Gilberto Freyre, que proporcionaram uma explicação “oficial” para a cultura brasileira. A década de 60 introduziu novos atores na cena política nacional, o que possibilitou o surgimento de teorias como a do desenvolvimento dependente de Fernando Henrique Cardoso e da fricção interétnica de Roberto Cardoso de Oliveira. A antropologia respondeu com uma interpretação de forma mais consistente e convincente das contradições vividas pelos diferentes segmentos culturais formadores da sociedade nacional, o que, por outro lado, veio também contribuir com uma aproximação diferente do antropólogo em relação aos seus informantes e com uma qualidade diferente na prática de pesquisa de campo. Uma prática que vem se caracterizando por um comprometimento diferenciado do cientista social em relação aos fatos por ele estudado o que favoreceu uma visão mais crítica em relação aos "perigos" da "participação observante”, isto é, da militância política. ${ }^{62}$ Conseqüentemente, as pesquisas têm sido realizadas, na sua maioria, em relação a nós mesmos e somente agora começa a existir um interesse por ultrapassar as fronteiras nacionais. Estamos vivenciando um momento de transição no contexto mundial e nacional e, portanto, começamos a perceber um deslocamento da perspectiva antropológica e da escolha de seu objeto que, com certeza, tem se manifestado na produção dos PPGAS, ${ }^{63}$ prometendo contribuições futuras mais diversificadas teoricamente.

Conseqüentemente, a antropologia sociocultural no Brasil além de se caracterizar pela existência de linhas de pesquisas que fazem parte recorrentemente de sua história - como por exemplo, etnologia, antropologia do campesinato, antropologia urbana - também tem se singularizado pela sua diversidade temática, ${ }^{64}$ tanto em relação ao seu objeto de estudo quanto nas metodologias empregadas, na textualização e nas tradições teóricas utilizadas. A história da antropologia social demonstra que no Brasil, a disciplina não pode e não deve ser definida em função da escolha de seu objeto de estudo.

${ }^{62}$ O compromisso do antropólogo em relação ao grupo estudado é diferente da militância política, isto é, como prática exclusivamente político-partidária. Este compromisso se manifesta principalmente pela solidariedade e honestidade no tratamento com os informantes.

${ }^{63}$ A necessidade de analisar a produção dos PPGAS criados recentemente no nordeste e sul do país, além do acompanhamento dos mais antigos é uma tarefa fundamental na atualidade, da crítica antropológica no país e, portanto, também no desenvolvimento da disciplina.

${ }^{64}$ Por exemplo, a diminuição relativa das pesquisas etnológicas na UNB nos anos 80 foi, na verdade, o crescimento das demais áreas temáticas. Consultar os anexos de Rubim (1996). 
Uma possível definição deve necessariamente considerar este aspecto plural da disciplina na percepção do mundo, da vida e da ciência. Ou seja: "O fato é que não é possível definir a antropologia com base num cânone sobre o qual todos concordariam” (Clifford, 1996, p. 10). Outra questão importante nessa história é que apesar das divergências e da multiplicidade substancial da antropologia entre nós, encontramo-nos organizados e unificados numa única instituição que tem conseguido refletir essa pluralidade: a Associação Brasileira de Antropologia. ${ }^{65}$

Qual a contribuição dos conhecimentos adquiridos nessas pesquisas para o avanço das teorias antropológicas entre nós e com o autoconhecimento da nossa sociedade? Excluindo-se o já exposto e, em última instância, o projeto da antropologia social não tem como objetivo a compreensão da realidade em sua totalidade. Esta tarefa é de responsabilidade das ciências sociais. Sociologia, ciência política e antropologia social estão unidas para alcançar este objetivo.

A antropologia social assume, neste conjunto, a tarefa de compreensão dos aspectos singularizadores da nação e, portanto, as suas pesquisas se desenvolveram mais em função de uma perspectiva microscópica no sentido da desmistificação das diferenças e da desnaturalização do poder, do preconceito e da harmonia social. No entanto, é imperativo que a disciplina não perca a perspectiva do todo. $\mathrm{O}$ que de fato, não aconteceu com a maioria de nossas pesquisas.

Nesses últimos vinte e cinco anos a antropologia no mundo e no Brasil se transformou, como também o próprio mundo e a própria história. Hoje, já não existe consenso em relação ao objeto de estudo da disciplina. O objeto de estudo da antropologia, de um modo geral, está inserido num conjunto de "outros": histórico, geográfico, cultural, intelectual, de classe, de gênero etc.

Conseqüentemente, a observação participante e os seus objetivos também se modificaram nesses últimos anos. Transformou-se o antropólogo que atualmente está mais consciente de seus limites enquanto representante da ciência, questionando a objetividade e a neutralidade de suas pesquisas e, portanto, a legitimidade do conhecimento produzido. Nossos informantes, por sua vez, estão mais sabedores de seus direitos, e encaram com mais perspicácia o trabalho do antropólogo. O relacionamento entre ambos possui

65 Como o constatado pelo último Cadastro de Teses e Dissertações em Antropologia da ABA, 1994/95, o número de seus sócios é praticamente o mesmo da quantidade de mestres e doutores formados em nossos PPGAS. 
hoje um significado diferenciado, apesar de ainda haver hierarquia. Mas, o respeito entre o antropólogo e seu informante é visível, existindo uma tentativa de unificação dos objetivos de ambos. A antropologia interpretativa e o que ficou conhecido como antropologia pós-moderna ${ }^{66}$ permitiu que se avançasse na discussão, contribuindo com o refinamento do pensamento e da prática do antropólogo. No entanto, a trajetória do pensamento antropológico, a tradição de seus clássicos e as experiências de pesquisa de campo acumuladas até então, não podem ser negadas como parece acontecer com alguns autores. ${ }^{67}$ Hoje, a necessidade da crítica constante ao pensamento antropológico é um dos consensos seguidos pelos antropólogos de todas as tradições.

Conseqüentemente, o projeto científico da antropologia no mundo atual não pode permanecer o mesmo do passado. $\mathrm{O}$ conhecimento antropológico abandonou, por exemplo, a pretensão de querer explicar a humanidade como um todo através da descoberta de "leis" gerais. A busca do conhecimento antropológico, atualmente, está associada à compreensão das diferenças quaisquer que sejam elas - para uma melhor convivência, desmistificando preconceitos e prepotências que venham justificar a violência e a opressão, superioridades ou verdades absolutas.

O objetivo prioritário da antropologia brasileira foi, nessas últimas décadas, o conhecimento do Brasil, o mapeamento do seu território e a compreensão da diversidade cultural de sua formação. Neste sentido, conjuntamente com as demais ciências humanas - a sociologia, a ciência política, a história e a economia - a disciplina tem efetivamente contribuído na construção de um pensamento social criativo e original sobre o país.

66 Que como afirmou Reynoso (1991) não é um movimento unitário.

67 Refiro-me a Stephen Tyler (1991, p. 300) que defende a antropologia pós-moderna como uma "voz libre”, isto é, possível de falar qualquer coisa. "La evocación - que es decir 'la etnografia' - es el discurso del mundo posmoderno, porque el mundo que hizo la ciencia, y esa ciencia hecha, han desaparecido, y el pensamiento científico es ahora un modo arcaico de conciencia que sobrevive por un tiempo, en una forma degradada, sin el contexto etnográfico que lo creó y lo sostuvo. El pensamiento científico sucumbió por haber violado la primera ley de la cultura, la que dice que 'cuanto más el hombre controla algo, más incontrolable se vuelven ambos’, en la retórica totalizadora de su mitología, la ciencia implicaba su propia justificación y pretendía controlar y tomar autónomo su discurso; y cuanto más controlaba su discurso sujetándolo al criterio de la prueba, más incontrolable se tornaba su discurso. Su propia atividad fragmentaba constantemente la unidad del conocimiento que ella pretendía. Cuanto más sabía, más quedaba por conocer” (Tyler, 1991, p. 298).

Horizontes Antropológicos, Porto Alegre, ano 3, n. 7, p. 97-128, nov. 1997 
Autores estrangeiros mais citados no mestrado da UNB, USP*, Museu Nacional e Unicamp nas décadas de 70 e $80^{* *}$.

\begin{tabular}{lccc}
\hline \multicolumn{1}{c}{ AUTORES } & DÉCADA DE 70 & DÉCADA DE 80 & TOTAL \\
\hline Lévi-Strauss & 204 & 286 & 490 \\
\hline Pierre Bourdieu & 92 & 172 & 264 \\
\hline Edmund Leach & 127 & 109 & 236 \\
\hline Victor Turner & 95 & 106 & 201 \\
\hline Karl Marx & 96 & 77 & 173 \\
\hline Marcel Mauss & 51 & 102 & 153 \\
\hline Irving Goffman & 68 & 66 & 134 \\
\hline Michel Foucault & 14 & 114 & 128 \\
\hline Clifford Geertz & 24 & 95 & 119 \\
\hline Mary Douglas & 58 & 56 & 114 \\
\hline Marshall Sahlins & 34 & 77 & 111 \\
\hline Evans-Pritchard & 34 & 71 & 105 \\
\hline Max Weber & 32 & 65 & 97 \\
\hline Durkheim & 18 & 72 & 90 \\
\hline Louis Dumont & 15 & 65 & 80 \\
\hline MaxGluckman & 28 & 49 & 77 \\
\hline Bronislaw Malinowski & 21 & 55 & 76 \\
\hline Raymond Firth & 42 & 29 & 71 \\
\hline Ward Goodnough & 58 & 3 & 61 \\
\hline Maurice Godelier & 36 & 21 & 57 \\
\hline Peter Berger & 17 & 34 & 51 \\
\hline Antonio Gramsci & 2 & 49 & 51 \\
\hline
\end{tabular}

Fonte: Dissertações em Antropologia Social da UNB, USP, MN e Unicamp. *Minha amostra; Novo Regimento.

Número e proporção de dissertacōes de mestrado em Antropologia Social da UNB, USP*, Museu Nacional e Unicamp nas décadas de 70, 80 e 90 (até 1994).

\begin{tabular}{ccccccccccc}
\hline \multicolumn{3}{c}{ QUANTIDADES } & \multicolumn{1}{c}{ PERCENTUAL (\%) } \\
\hline Década & UNB & USP & MN & CAMP & Total & UNB & USP & MN & CAMP & Total \\
\hline 70 & 26 & 12 & 63 & 17 & 118 & $5,29 \%$ & $2,44 \%$ & $12,83 \%$ & $3,46 \%$ & $24,02 \%$ \\
\hline 80 & 33 & 43 & 68 & 38 & 182 & $6,72 \%$ & $8,75 \%$ & $13,84 \%$ & $7,73 \%$ & $37,04 \%$ \\
\hline 90 & 30 & 37 & 69 & 55 & 191 & $6,10 \%$ & $7,53 \%$ & $14,05 \%$ & $11,20 \%$ & $38,88 \%$ \\
\hline Total & 89 & 92 & 200 & 110 & 491 & $18,12 \%$ & $18,73 \%$ & $40,73 \%$ & $22,40 \%$ & $100 \%$ \\
\hline
\end{tabular}

Fonte: Pós-Graduação em Antropologia Social da UNB, USP, MN e Unicamp. * Minha amostra; Novo Regimento.

Horizontes Antropológicos, Porto Alegre, ano 3, n. 7, p. 97-128, nov. 1997 
Autores nacionais mais citados no mestrado da UNB, USP*, Museu Nacional e Unicamp nas Décadas de 70 e $80^{* *}$.

\begin{tabular}{lccc}
\hline \multicolumn{1}{c}{ AUTORES } & DÉCADA DE 70 & DÉCADA DE 80 & TOTAL \\
\hline Roberto Da Matta & 126 & 188 & 314 \\
\hline Gilberto Velho & 52 & 161 & 213 \\
\hline Roberto Cardoso de Oliveira & 44 & 74 & 118 \\
\hline Eunice Durham & 44 & 74 & 118 \\
\hline Octávio lanni & 24 & 49 & 97 \\
\hline Peter Fry & 9 & 68 & 77 \\
\hline Júlio Cézar Melatti & 17 & 59 & 76 \\
\hline Otávio Velho & 43 & 39 & 82 \\
\hline Antônio Cândido & 20 & 43 & 63 \\
\hline Paul Singer & 30 & 30 & 60 \\
\hline Caio Prado Jr. & 32 & 19 & 51 \\
\hline Anthony & 11 & 37 & 48 \\
\hline Fernando Henrique Cardoso & 19 & 27 & 46 \\
\hline Florestan Fernandes & 8 & 37 & 45 \\
\hline Maria Isaura Pereira de Queiroz & 18 & 25 & 43 \\
\hline Afrânio Garcia Jr. & 20 & 22 & 42 \\
\hline Carlos Rodrigues Brandão & $\bullet$ & 38 & 38 \\
\hline Roque de Barros Laraia & 10 & 28 & 38 \\
\hline Eduardo Viveiros de Castro & 1 & 28 & \\
\hline
\end{tabular}

Fonte: Dissertações em Antropologia Social da UNB, USP. MN e Unicamp. *Minha amostra; Novo Regimento.

\section{Referências}

ALENCASTRO, L. F. Não sabem dizer coisa certa. Revista Brasileira de Ciências Sociais, ano 6, n. 16, p. 61-65, jul. 1991.

ARAGÃO, L. T. de. Tradition et modernisme dans la Ville Nouvelle de St. Quentin-en-Yvelines: utilisation des méthodes anthropologiques dans l'étude d'une Ville Nouvelle. 1980. Tese (Doutorado)-École des Hautes Études en Sciences Sociales, Paris, 1980. 
ARANTES, P. E. Um departamento francês de ultramar: estudos sobre a formação da cultura uspiana (uma experiência nos anos 60). Rio de Janeiro: Paz e Terra, 1994.

ARAÚJO, B. J. de (Org.). A crise da USP. São Paulo: Brasiliense, 1980.

ASSOCIAÇÃO BRASILEIRA DE ANTROPOLOGIA. Cadastro de teses $e$ dissertações em antropologia. Rio de Janeiro, 1994/95.

AZEREDO, P. R. Antropólogos e pioneiros: a história da Sociedade Brasileira de Antropologia e Etnologia. São Paulo: FFLCH/USP, 1986.

CARDOSO, R. C. L. Aventuras de antropólogos em campo ou como escapar das armadilhas do método. In: CARDOSO, R. C. L. (Org.). A aventura antropológica. Rio de Janeiro: Paz e Terra, 1986.

CARDOSO DE OLIVEIRA, R. Sobre o pensamento antropológico. Rio de Janeiro: Tempo Brasileiro: MCT: CNPq, 1988.

CARDOSO DE OLIVEIRA, R. O movimento dos conceitos em antropologia. Revista de Antropologia, São Paulo, n. 36, p. 13-31, 1994.

CASTRO FARIA, L. de. Museu Nacional: o espetáculo e a excelência. In: CASTRO FARIA, L. de. Antropologia: espetáculo e excelência. Rio de Janeiro: Tempo Brasileiro: Editora UFRJ, 1993.

CLIFFORD, J. As fronteiras da antropologia. Boletim da Associação Brasileira de Antropologia, n. 25, mar. 1996.

CORRÊA, M. As ilusões da liberdade: a Escola Nina Rodrigues e a antropologia no Brasil. 1982. Tese (Doutorado em Ciência Política)Faculdade de Filosofia, Letras e Ciências Humanas, Universidade de São Paulo, São Paulo, 1982. 2 v.

CORRÊA, M. Os atos e os autos: representações jurídicas de papéis sexuais. Rio de Janeiro: Graal, 1983.

CORRÊA, M. História da Antropologia no Brasil (1930-1960): testemunhos: Emílio Willems e Donald Pierson. São Paulo: Vértice: Editora da Unicamp, 1987. 
CORRÊA, M. A antropologia no Brasil (1960-1980). In: MICELI, S. (Org.). História das Ciências Sociais no Brasil: vol. 2. São Paulo: Sumaré, 1995.

DA MATTA, R. Relativizando: uma introdução a antropologia social. Petrópolis: Vozes, 1987.

DURHAM, E. A pesquisa antropológica com populações urbanas: problemas e perspectivas. In: CARDOSO, R. C. L. (Org.). A aventura antropológica. Rio de Janeiro: Paz e Terra, 1986.

FERNANDES, A. M. A construção da ciência no Brasil e a SBPC. Brasília: Editora da UNB: ANPOCS: CNPq, 1990.

FERNANDES, F. A questão da USP. São Paulo: Brasiliense, 1984.

FÍGOLI, L. H. G. Identidade étnica e regional: trajeto construtivo de uma identidade social. 1982. Dissertação (Mestrado em Antropologia Social)Departamento de Antropologia, Universidade de Brasília, Brasília, 1982.

FLORES, E. D. P. de. A pós-graduação em Educação: o caso da Unicamp na opinião de professores, ex-alunos e alunos. 1995. Tese (Doutorado em Educação)-Faculdade de Educação, Universidade Estadual de Campinas, Campinas, 1995.

FONSECA, C. Crime, corps, drame et humour: famile et quotidien dans la culture populaire. 1993. Tese (Doutorado)-Université de Nanterre, Nanterre, 1993.

FORJAZ, M. C. S. Cientistas e militares no desenvolvimento do CNPq (19501985). Boletim Informativo Bibliográfico de Ciências Sociais, Rio de Janeiro, n. 28, p. 71-99, 2. sem. 1989.

GEERTZ, C. El antropólogo como autor. Barcelona: Paidos, 1989.

LAZARIN, M. A. A descida do rio Punis (uma experiência de contato interétnico). 1981. Dissertação (Mestrado em Antropologia Social)Departamento de Antropologia, Universidade de Brasília, Brasília, 1981. 
LIMA, E. J. da S. A criação da Unicamp: administração e relações de poder numa perspectiva histórica. 1989. Dissertação (Mestrado em Educação)Faculdade de Educação, Universidade Estadual de Campinas, Campinas, 1989.

LIMONGI, F. Mentores e clientelas da Universidade de São Paulo. In: MICELI, S. (Org.). História das Ciências Sociais no Brasil: vol. 1. São Paulo: IDESP: Vértice: FINEP, 1989.

LOSCHIAVO DOS SANTOS, M. C. (Org.). Maria Antônia: uma rua na contramão. São Paulo: Nobel, 1988.

MARANHÃO, T. P. Náutica e classificação ictiológica em Icaraí/Ceará: um estudo em antropologia cognitiva. 1975. Dissertação (Mestrado em Antropologia Social)-Departamento de Antropologia, Universidade de Brasília, Brasília, 1975.

MASSI, F. P. Franceses e norte-americanos nas ciências sociais brasileiras (1930-1960). In: MICELI, S. (Org.). História das Ciências Sociais no Brasil: vol. 1. São Paulo: IDESP: Vértice: FINEP, 1989.

MENDOZA, E. S. G. Uma “aldeia” de antropólogos: a antropologia em Brasília. 1994. Dissertação (Mestrado em Antropologia Social)-Departamento de Antropologia, Universidade de Brasília, Brasília, 1994.

MENEGUEL, S. Zeferino Vaz e a Unicamp: uma trajetória e um modelo de universidade. 1994. Dissertação (Mestrado em Educação)-Faculdade de Educação, Universidade Estadual de Campinas, Campinas, 1994.

PEIRANO, M. Proibições alimentares numa comunidade de pescadores. 1975. Dissertação (Mestrado em Antropologia Social)-Departamento de Antropologia, Universidade de Brasília, Brasília, 1975.

PEIRANO, M. Anthropology of anthropology: the Brazilian case. 1981. Tese (Ph.D.)-Harvard University, Boston, 1981.

PEIRANO, M. Uma antropologia no plural: três experiências contemporâneas. Brasília: Editora da UNB, 1991. 
PEIRANO, M. Os antropólogos e suas linhagens. In: CORRÊA, M.; LARAIA, R. de B. (Org.). Roberto Cardoso de Oliveira: homenagem. Campinas: IFCH/ Unicamp, 1992.

RABIELA, T. R. Las agrupaciones de antropólogos en México: una historia de familia. 1996. Comunicação apresentada à Mesa Redonda "Formas de Organização e Intervenção Social dos Antropólogos”, XX Reunião da ABA, Salvador, 15-18 de abril de 1996.

RATIER, H. E.; STAGNARO, A. A. Organización de la comunidad de antropólogos. 1996. Comunicação apresentada à Mesa Redonda "Formas de Organização e Intervenção Social dos Antropólogos”, XX Reunião da ABA, Salvador, 15-18 de abril de 1996.

REIS, F. W. O tabelão e a lupa: teoria, método generalizante e idiografia no contexto brasileiro. Revista Brasileira de Ciências Sociais, São Paulo, ano 6, n. 16, p. 27-42, jul. 1991.

REYNOSO, C. (Comp.). El surgimiento de la antropología posmoderna. México: Gedisa, 1991.

RIBEIRO, D. UNB: invenção e descaminho. Rio de Janeiro: Avenir, 1978a.

RIBEIRO, D. A universidade necessária. Rio de Janeiro: Paz e Terra, 1978b.

RIBEIRO, D. Testemunho. São Paulo: Siciliano, 1990.

ROMANO, J. O. Índios proletários em Manaus: o caso dos SateréMawé citadinos. 1982. Dissertação (Mestrado em Antropologia Social)Departamento de Antropologia, Universidade de Brasília, Brasília, 1982.

RUBIM, C. de R. Antropólogos brasileiros e a antropologia no Brasil: a era da pós-graduação. 1996. Tese (Doutorado em Ciências Sociais)-Instituto de Filosofia e Ciências Humanas, Universidade Estadual de Campinas, Campinas, 1996.

SCHADEN, E. Os primeiros tempos da antropologia em São Paulo. Anuário Antropológico 82, Rio de Janeiro: Tempo Brasileiro, p. 251-258, 1984. 
SCHWARCZ, L. M. O nascimento dos museus brasileiros (1870-1910). In: MICELI, S. (Org.). História das Ciências Sociais no Brasil: vol. 1. São Paulo: IDESP: Vértice: FINEP, 1989.

SCHWARCZ, L. M. O espetáculo das raças: cientistas, instituições e questão racial no Brasil, 1870-1930. São Paulo: Companhia das Letras, 1993.

SCHWARCZ, R. Um seminário de Marx. Folha de S. Paulo, São Paulo, 8 out. 1995. Caderno MAIS!, p. 4-5.

SCHWARTZMAN, S. As ciências sociais nos anos 90. Revista Brasileira de Ciências Sociais, ano 6, n. 16, p. 51-60, jul. 1991.

SOUZA CAMPOS, E. de. História da Universidade de São Paulo. São Paulo: USP, 1954.

SOUZA LIMA, A. C. de. Aos fetichistas, ordem e progresso: um estudo do campo indigenista no seu estado de formação. 1985. Dissertação (Mestrado em Antropologia Social)-Museu Nacional/UFRJ, Rio de Janeiro, 1985.

SOUZA LIMA, A. C. de. Os museus de história natural e a construção do indigenismo: notas para uma sociologia das relações entre campo intelectual e campo político no Brasil. Revista de Antropologia, v. 30/31/32, p. 277-329, 1989.

TAVARES, M. das G. de P. Um estudo de tomada de decisão (decision making) na pesca artesanal: Icaraí/Ceará. 1975. Dissertação (Mestrado em Antropologia Social)-Departamento de Antropologia, Universidade de Brasília, Brasília, 1975.

TYLER, S. Etnografía posmoderna: desde el documento de lo oculto al oculto documento. In: CLIFFORD, J.; MARCUS, G. (Ed.). Retoricas de la antropología. Barcelona: Júcar, 1991.

VALENTE, A. L. E. F. Política e relações raciais: os negros e as eleições paulistas de 1982. 1984. Dissertação (Mestrado em Ciências Sociais/ Antropologia Social)-Faculdade de Filosofia, Letras e Ciências Humanas, Universidade de São Paulo, São Paulo, 1984. 
VELHO, O. G. A. Antropologia para sueco ver. Dados, Rio de Janeiro, v. 23, n. 1, p. 79-91, 1980.

WAGLEY, C. Amazon town: a study of man in the tropics. New York: The Macmillan Company, 1953.

WILLEMS, E. Cunha, tradição e transição em uma cultura rural do Brasil. São Paulo: Diretoria de Publicidade Agrícola da Secretaria de Agricultura, 1947.

WOORTMANN, K. A. Crônica (informativa, levemente crítica e um tanto apologética) de um programa de pós-graduação: a antropologia na UNB. Série Antropologia, Brasília, n. 142, 1993.

ZARUR, G. de C. L. Seafood gatherers in mullet springs: economic rationality and the social system. 1975. Tese (Ph.D.)-University of Florida, Gainesville, 1975. 